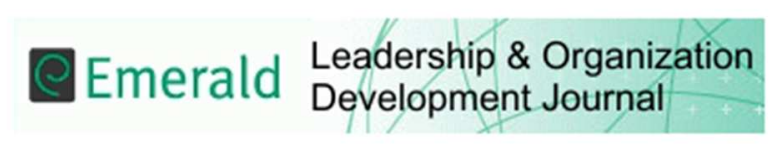

\title{
Combinative aspects of leadership style and emotional intelligence
}

\begin{tabular}{|r|l|}
\hline Journal: & Leadership \& Organization Development Journal \\
\hline Manuscript ID & LODJ-04-2014-0082.R3 \\
\hline Manuscript Type: & Research Paper \\
\hline Keywords: & Leadership style, Configuration, Emotional Intelligence \\
\hline \multicolumn{2}{|l}{} \\
\hline
\end{tabular}

SCHOLARONE $^{\text {M }}$
Manuscripts 


\section{Combinative aspects of leadership style and emotional intelligence}

\section{Introduction}

Leadership style has traditionally been construed as the extent to which an individual emphasizes or displays particular types of leadership (e.g., consideration, initiating structure, transactional, transformational) and measured by the frequency or intensity of specific leadership behaviors or attitudes using multiple-items and Likert scales. This paradigm, although fruitful, is limited in some ways as it overlooks micro aspects of leadership style that may profoundly influence the impact of leadership on followers emotional states and ultimately on how followers respond to the leader.

The importance of emotions in the workplace renders it vital for leaders to be emotionally intelligent (Goleman, 1995) especially because leadership is an emotion-inducing phenomenon. Leadership is fundamentally an emotion-management process wherein leaders manage their own emotions and those of their followers (Yukl, 2002).

Although there is a considerable body of literature on leadership and emotional intelligence, a key question remains: Does the emotional intelligence of leaders influence micro aspects of leadership style such as preferences for different ways of combining specific leadership behaviors? The purpose of our study is to address this question. In doing so, we contribute to the literatures on leadership and emotional intelligence in two ways: Firstly, we examine micro aspects of leadership. Specifically, the preferences of leaders for using different leadership typologies (see Doty and Glick, 1994) or styles that differ in terms of how particular leadership behaviors are combined. Furthermore, we use a vignette-based methodology to assess leadership style rather than the traditional multiple-item, Likert-scale 
approach. Secondly, we examine whether emotional intelligence influences micro aspects of leadership style and thus build on the work of Casimir (2001), which showed that followers preferred different leadership styles that differ in terms of how particular leadership behaviors are combined.

\section{Emotions in the workplace}

Four categories of affect have been identified: meta-emotional abilities (e.g., emotional intelligence), dispositional traits (e.g., neuroticism), moods (e.g., sadness), and emotions (e.g., anxiety) (Barsade and Gibson, 2007). Emotions differ from moods in terms of their specificity, intensity, and duration. Compared to moods, emotions are more likely to be attributable to a particular incident, are more likely to be associated with a particular response, are more intense, and are of shorter duration than moods (Frijda, 1993). We focus on emotions rather than moods because emotions are more easily attributable to a specific event (e.g., car breaking down) or a target person's (e.g., the leader) behavior than are moods (Frijda, 1993).

Emotions are evoked by events that occur in all domains of our lives including the workplace. Emotional reactions to workplace events mediate the relationships between these events and various attitudinal and behavioral outcomes (Affective Events Theory; Weiss and Cropanzano, 1996): For example, being shouted at by one's supervisor is likely to evoke negative emotions such as anger and anxiety (Fox and Stalworth, 2010), which may then reduce attitudes such as job satisfaction and ultimately behaviors such as turnover.

Emotions play a fundamental role in both decision making and behavior (Adolphs and Damasio, 2001) because people are likely to make decisions and behave in ways that maximize positive emotions and minimize negative ones (Frijda, 1992). Emotions prime mood-congruent thoughts, memories, and cognitive constructs (e.g., schemas) (Bower, 1991; 
Bower and Forgas, 2001). Positive emotions can enhance creativity (Fredrickson, 2001) and positive emotions after the working day can improve levels of hope the following day (Ouweneel, Le Blanc, Schaufeli, and van Wijhe, 2012). Leaders therefore need to foster healthy work environments and foster positive interpersonal relationships (Cartwright and Cooper, 2009) even though negative emotions can increase performance under certain conditions in the short term (Misumi, 1985).

\section{Leadership}

Day-to-day leadership in many organizations comprises, to a large extent, task-oriented behaviors (e.g., scheduling the work of followers and providing them with instructions/advice) and socio-emotional behaviors (e.g., being approachable and listening to followers) (Judge, Piccollo and Ilies, 2004). Managers spend approximately a quarter of their time on behaviors that are related to the performance of their subordinates (e.g., actually sampling the work of subordinates) (Komaki, Zlotnick and Jensen 1986). For example, American managers, Russian managers, and knowledge managers spend most of their time on traditional management activities (e.g., planning, monitoring and controlling) and human resource management (e.g., motivating staff by conveying appreciation or increasing job challenge) (Asllani and Luthans, 2003).

Task-oriented leadership comprises a diverse range of behaviors including assigning particular jobs to subordinates, emphasising deadlines (Bruno and Lay, 2008; Fleishman, 1973; Halpin, 1955), checking that subordinates observe rules and regulations, and pressuring them to work hard (Misumi, 1985). Thus, an important aspect of task-oriented leadership is Pressure, which involves pressuring subordinates to work hard and maintain quality standards 
by sampling their work, monitoring their performance, and emphasizing deadlines. We therefore examine the effects of Pressure.

Socio-emotional leadership is multifaceted and comprises behaviors such as providing encouragement and maintaining amiable relationships with subordinates (Halpin, 1955; James, Mann and Creasy, 2007) that are characterized by mutual trust, respect for followers' ideas, and consideration of their feelings (Lee, Gillespie, Mann and Wearing, 2010). Socioemotional leadership also involves supportive behaviors such as expressing appreciation for followers' efforts (Misumi and Peterson, 1985) and showing concern for their welfare (House, 1971; Bass, 1997). Thus, Support is a core component of socio-emotional leadership (Yukl, 2002). We therefore examine the effects of Support.

The emotional effects of pressure and support

Pressure can result in followers experiencing negative emotions (e.g., anxiety, guilt or shame) even if they perceive the Pressure as an appropriate (i.e., justified) negative evaluation from the leader (e.g., disapproval) of their efforts or even if they perceive the Pressure as a legitimate effort by the leader to meet an upcoming deadline. Followers who perceive Pressure as inappropriate might also experience negative emotions such as resentment if they believe the leader is placing unnecessary demands on them or is abusing formal authority for personal reasons. Alternatively, Pressure can evoke positive emotions (e.g., enthusiasm and optimism) in followers if they perceive it as an expression of the leader's confidence in their ability to achieve higher levels of performance (House, 1977). 
Support from the leader increases satisfaction with the leader and reduces the stress levels of followers. Reduced levels of stress have been shown to be negatively related to absenteeism, turnover, alcoholism, and drug abuse (Yuk1, 2002). We assume, as do other researchers (e.g., Peterson, Smith and Tayeb, 1993), that the positive effects of supportive leadership are due to the positive emotions that Support evokes in followers. Support can, however, also evoke negative emotions in followers. For instance, followers will perceive Support negatively if they believe the leader is not genuinely concerned for their welfare and is only utilizing Support to manipulate them (e.g., using ingratiation as an influence tactic).

Pressure tends to produce negative emotions (e.g., anxiety and resentment) in followers (Misumi, 1985) and Support is thus required to reduce any anxiety or resentment (Hafsi, 1988) or transform these negative emotions into constructive arousal (Peterson et al., 1993). Support generally provides a psychological counterbalance to Pressure (Misumi and Peterson, 1985) and thus influences perceptions of Pressure. For instance, Pressure on its own might be seen as imposed control (House 1987), whereas Pressure might be seen as warranted urgency when it is combined with Support.

\section{Combinative aspects of leadership style}

An insight into the importance of micro aspects of leadership style, such as how specific behaviors are configured by leaders, was provided by Fulk and Wendler (1982). They found that achievement-oriented leadership has functional and dysfunctional effects depending on the other leadership behaviors with which it is combined. Followers perceive achievement oriented leadership as unacceptable when it is not combined with resource support and contingent reward and when it is combined with arbitrary and punitive behaviors. 
The findings of an experiment that was conducted almost half a century ago shows the importance of configuration. Marigonda (1968, cited in Pavlova, Sokolov and Sokolov, 2005) presented two pairs of parallel lines to participants. One pair of lines was tilted to the right (i.e., //) and the other pair was tilted to the left of the vertical position (i.e., II). For the pair tilted to the right, the line on the left was perceived as 'dominant and bossy' and the line on the right was perceived as 'submissive' whereas the converse was found for the pair that was tilted to the left.

Perceptions of the relationship between innocuous stimuli such as a pair of lines therefore appear to be influenced by simple variations in their configuration. This finding is consistent with our proposition that perceptions of the same two leadership behaviors will be influenced by the manner in which they are configured.

Followers perceive leadership behaviors as holistic clusters or configurations rather than as disconnected separate events and prefer some configurations over others because of the different meanings they attribute to different configurations (Casimir, 2001). The different interpretations or meanings given to different combinations of the same leadership behaviors evoke different emotions in followers. These emotional responses to leadership style are important because they influence workplace attitudes and ultimately behavior (Mignonac and Herrbach, 2004).

Different leadership typologies or leadership styles can be created using three variables (i.e., combinative aspects) that describe the sequencing and temporal spacing of the behaviors: i) Order, which refers to the sequencing of the behaviors; ii) Temporality, which refers to the interval between the provision of the behaviors; and iii) Constancy, which refers to whether the behaviors are always combined in the same way. 
Many leadership typologies or combinative styles can be developed based on Order, Temporality and Constancy. However, for the purpose of this research, four typologies will be examined in relation to two types of leadership behavior: Pressure and Support. These four typologies are equivalent in that all of them consist of the same Pressure and Support statements. The four differ, however, in how the Pressure and Support statements are configured. The four typologies are as follows: i) Support is always provided immediately after Pressure (i.e., the After style); ii) Support is always provided immediately before Pressure (i.e., the Before style); iii) Support is provided either immediately before or immediately after Pressure (i.e., the Either style); and iv) Pressure is provided first and later on (i.e., thirty minutes) Support is provided (i.e., the Delayed style). The After and Before styles differ in terms of Order, and both of them differ from the Either style in terms of Constancy. The Delayed style differs from the three other styles in terms of Temporality.

There is some evidence to support the claim that Order, Temporality, and Constancy influence perceptions of Pressure and Support. In a vignette-based study (Casimir, 2001) that described a stressful workplace, followers differentiated between the four typologies described earlier. Specifically, followers preferred the Before style over the three other styles whilst the Delayed style was the least popular.

One explanation for the popularity of the Before style is the mitigating or "psychological cushioning" effect of Support on the negative emotions that tend to be evoked by Pressure. Providing Support immediately before Pressure establishes a positive emotional context within which Pressure is perceived, and thus psychologically cushions followers from the negative emotions that are likely to be evoked by Pressure. Providing Support immediately 
before Pressure is also likely to make the leader appear considerate, respectful and/or sympathetic to the stressors followers face and thus reduces the likelihood of followers perceiving Pressure as disapproval or imposed control, which is likely to evoke negative emotions. This rationale is consistent with some personality research (i.e., Asch, 1946) that has shown the first adjectival descriptor sets up a context or an initial impression within which following descriptors are embedded: For example, a person who is described as intelligent, impulsive, and envious is seen in a more positive light than a person who is described as envious, impulsive, and intelligent (Asch, 1946).

An alternative explanation to the psychological cushioning effect of Support is that different typologies or combinative styles correspond to different leadership scripts. Scripts can be considered as a linear ordering of events (Nottenberg and Shoben, 1980) that influences the perception of the events (Gioia and Poole, 1984; Markus and Zajonc, 1985). Different orderings of events will arguably evoke different emotions such that orderings that are congruent with one's preferred script will generally evoke positive emotions whereas those that are incongruent will generally evoke negative emotions. As Hull (1945) pointed out, apologising after stepping on someone's toes would be a courtesy whereas apologising before stepping on someone's toes would be an affront. In conclusion, the implications of context effects and scripts are that perceptions of leadership behaviors and the subsequent emotions they evoke in followers depend on how the behaviors are combined. 


\section{Emotional intelligence and combinative aspects of leadership}

Leadership behaviors can evoke a wide spectrum of emotions in followers ranging from optimism and joy to frustration and anger (Zineldin and Hytter, 2012), and these emotions strongly influence the overall work experience and behavior of followers. Emotions play a central role in the leadership process because leadership is essentially an emotional process wherein leaders display emotion and attempt to evoke emotion in followers (George, 2000). For example, frustration and optimism mediate the relationship between leadership and follower performance (McColl-Kennedy and Anderson, 2002).

Despite the controversy in the literature about the merits of emotional intelligence with regards to leadership effectiveness, emotional intelligence appears to be an important attribute for effective leadership (Goleman, Boyatzis, and McKee, 2004). Emotional intelligence helps leaders to deal effectively not only with their own emotions but also those of their followers (Peterson and Luthans, 2003). Effective leaders are able to arouse positive emotions in their followers and can alleviate followers' negative emotions during times of crisis (Bono, Folds, Vincent and Muros, 2007). Leaders with high levels of emotional intelligence are apt at integrating emotional considerations when considering alternative solutions to problems and behaving in ways that are considerate and respectful of their own emotions and those of others (Salovey and Mayer, 1990).

According to Mayer and Salovey (1997), emotional intelligence comprises four abilities: i) awareness of one's emotions; ii) management of one's emotion; iii) awareness of others' emotion; and iv) management of others' emotion. The ability to appraise and manage one's emotion allows one to choose socially adaptive responses. The ability to appraise the 
emotions of others allows one to accurately gauge the affective responses of others. The management of emotion represents the ability to monitor, evaluate, and regulate one's own emotions and those of others. Regulating emotions facilitates the mood enhancement of oneself and also others, and allows one to positively motivate others. The management of emotion allows the harnessing of one's own emotion to facilitate performance through the use of flexible planning, creative thinking, and motivating one-self and others (Côté et al., 2010; Lopes et al., 2005).

Emotional intelligence has been shown to be linked to leadership. High-performing managers have greater self-awareness than do average-performing managers (Bruno and Lay, 2008; Church, 1997), leaders with high emotional intelligence select more effective behaviors than do leaders with low emotional intelligence (Caruso, Mayer and Salovey, 2002), and emotional intelligence is positively related to leadership effectiveness (Kerr et al., 2006), follower satisfaction and extra-role behavior (Wong and Law, 2002).

The skilful application of task-coordination behaviors and supporting-developmental behaviors requires emotional intelligence (Wolff, Pescosolido and Druskat, 2002). The ability to accurately perceive the emotions of followers from cues such as their language, tone, and behavior enables the leader to behave in ways that do not evoke negative emotions in followers (Mayer and Salovey, 1997). The ability to utilize one's own emotions facilitates a leader's capability to make positive emotions available to followers thereby motivating them (Caruso et al., 2002). Finally, the ability to regulate one's own emotions allows leaders to cope with stress and address the problems underlying the stress (Mayer and Salovey, 1993). 


\section{Hypothesis development}

The ability to control one's own emotions allows leaders to cope with the demands of a stressful work environment and adjust their emotions so that they are appropriate for the task at hand. Leaders who are better at controlling their own emotions are also better at evoking positive emotions in followers (Bass and Stogdill, 1990).

The ability to read one's own emotions accurately facilitates emotional self-control. Leaders who are aware of their own emotions are better placed to control their emotions and subsequently consider the emotional needs of followers.

The ability to accurately perceive the emotions of others from cues such as language, tone, appearance and behavior allows leaders to be aware of and sensitive to followers' emotional reactions to the leader's behavior. Leaders with this ability should be able to detect the negative impact that Pressure has on the emotions of followers.

The ability to use one's emotions to motivate oneself and facilitate goal attainment should help leaders not only to motivate themselves but also their followers via a social contagion process. According to Self-Determination Theory (Deci and Ryan, 2000), intrinsic motivation tends to positively impact performance. Leaders who use their emotions to motivate themselves and others in order to attain goals would therefore prefer to avoid inducing negative emotions in followers because negative emotions will eventually have an adverse effect on follower wellbeing and ultimately on follower performance.

We think the leader's emotional intelligence influences the leader's combinative style. Emotional intelligence should increase the leader's awareness of the negative emotions that Pressure can evoke in followers. Emotional intelligence should also increase the likelihood 
of a leader being aware that follower perceptions of Pressure and Support and the capacity of Support to counteract the negative emotional effects of Pressure are influenced by how Pressure and Support are configured.

As mentioned earlier, of the four combinative styles, the Before style is the one that is most likely to minimize the likelihood of Pressure evoking negative emotions in followers. In other words, as emotional intelligence increases, leaders should become more likely to prefer to psychologically cushion followers from the negative effects of Pressure, particularly in a highly stressful work environment. We therefore propose the following hypothesis:

Hypothesis 1 - Leaders who prefer the Before style have higher levels of emotional intelligence than do leaders who prefer the three other styles.

Pressure from the leader to work harder or more efficiently is essentially the application of the leader's formal authority over the follower and reveals the power distance between the leader and the follower. Pressure that is provided without Support is thus likely to evoke negative reactions from subordinates as it can be interpreted as autocratic leadership or as imposed control (Casimir, 2001). We think that long delays between Pressure and Support are generally undesirable because delayed Support exposes followers to any negative emotions that might be induced by Pressure. Delayed Support is thus less effective than contiguous Support at reducing the negative emotions that Pressure evokes. We therefore propose the following hypothesis:

Hypothesis 2 - Leaders who prefer the Delayed style have lower levels of emotional intelligence than do leaders who prefer the three other styles.

\section{Method}

Sample

Data were obtained from 204 full-time managers/supervisors (102 males, 102 females) in 
Australia. Braun and Clarke (2004) advise collecting data from a sample of 200 or more when using vignettes in large projects. The average age of the respondents is 40.5 years (SD $=0.8)$ and their average work experience is 20.6 years $(\mathrm{SD}=11.4)$. The highest level of education for respondents is as follows: Seven completed primary education, 91 completed secondary education, 98 completed tertiary education, and eight completed postgraduate education.

\section{Procedure}

We informed managers and supervisors of our study and invited them to participate. We gave the questionnaire to those managers/supervisors who volunteered to participate in the study and asked them to complete it whilst at work. Participants were informed that their responses would remain anonymous and confidential.

\section{Measures}

We developed a vignette to create an organizational context for the use of the four combinative leadership styles that we were testing. A vignette is a brief description of a setting or a short story in written or pictorial form that is provided to participants for their comments or opinions on the phenomena presented in the vignette (Barter and Renold, 2000).

There are several issues that need to be considered when designing a vignette (Braun and Clarke, 2004). The issues relevant to our study are ensuring the scenario is plausible and relevant to our participants, using language that is easy to read and unambiguous, and providing sufficient detail on relevant factors without making the vignette overly complex. 
An advantage of using a vignette is that it is not feasible to directly observe managers nor is it preferable to do so due to observer effects. Additionally, vignettes simplify complex social systems (e.g., organizations) that can obscure the phenomena being investigated (e.g., organizational leadership) and in doing so allow specific and relevant aspects of the social system to be made more salient (Corkery, 1992).

In the vignette, we described a stressful workplace scenario in which managers were under a lot of pressure to ensure their staff performed well. We used this context because it would rationalize the use of Pressure. We also mention in the vignette the need for managers to use both Pressure and Support. We mentioned this to rationalize combining the two types of leadership behaviour. We kept our description of the workplace vague in order for it to be appropriate for both blue-collar and white-collar employees.

We trialled our vignette on several colleagues and based on their comments made some changes to the wording and ordering of information. The vignette is as follows:

\section{The Workplace Situation}

Please imagine that you are a manager in a highly stressful workplace. An increasing workload has forced employees in your organization to improve their performance. Your staff are stressful because they have demanding performance targets. As a manager, your job is stressful because your boss expects a lot from you and your performance depends on the performance of your staff. 
As a manager, you have to push those members of your staff who are not achieving their performance goals (i.e., you have to provide Pressure). Additionally, you have to show your staff that you are aware of their stressful situation and that you appreciate their efforts (i.e., you have to provide Support).

We provided an example of a Pressure statement and a Support statement, which were derived from Misumi and Peterson's (1985) delineation of typical task-oriented behaviors (i.e., Pressure) and typical socio-emotional behaviors (i.e., Support). The Pressure statement was "You have to work faster because you are behind schedule" and the Support statement was "I know you have been busy lately and I appreciate the hard work that you have done".

We used the four combinative leadership typologies or styles mentioned earlier that were developed by Casimir (2001): After Style, Before Style, Either Style, and Delayed Style. The four styles were identified with the letters A, B, C and D instead of names because names can evoke stereotypes. A Latin Square design was used to counterbalance any serial-order effects. Four different versions of the questionnaire were therefore used. Respondents were required to rank the different ways of combining the Pressure statement and the Support statement according to how they as managers would speak to their staff.

\section{Emotional intelligence}

There is debate in the literature regarding the measurement of emotional intelligence. One perspective is that emotional intelligence is an ability and therefore needs to be measured via ability tests such as the Mayer-Salovey-Caruso Emotional Intelligence Test (MSCEIT; Mayer, 
Salovey and Caruso, 2002) that include tasks such as identifying emotions in photographs of faces and rating the effectiveness of different emotional-regulation strategies in intrapersonal and interpersonal situations.

A problem with tests of emotional intelligence such as the MSCEIT is that they consist of tasks that are "static" and that provide limited information about the person whose emotions are being appraised. In actual settings, people are exposed to a myriad of information about a particular individual. This additional information allows them opportunities to assess a person's emotional state more thoroughly as they can take into consideration the person's emotional-display idiosyncrasies: For example, some people may tend to smile when nervous. Additionally, the "correct" response is itself biased by normative expectations about a person's response to a particular situation (e.g., one's upcoming birthday party).

The other perspective on the measurement of emotional intelligence is that it is a trait and therefore should be measured via self-report. That is, emotional intelligence is a composite of emotion-related self-perceptions. One of the problems associated with measuring emotional intelligence via self-report is that self-report data are susceptible to faking.

Although there are several tests of emotional intelligence, most of them are lengthy. For example, the Mayer, Salovey and Caruso Emotional Intelligence Test comprises 141 items and takes about 30 minutes to complete (Mayer, Salovey, and Caruso, 2000). Furthermore, the validity and reliability of some short-form emotional intelligence questionnaires, such as Goleman's (1995) 10-item EI questionnaire and Weisinger's (1998) short-form EI questionnaire are not well established.

Wong and Law (2002) developed a based on Mayer and Salovey's model of emotional 
intelligence. Wong and Law's (2002) 16-item measure of emotional intelligence that comprises four dimensions: i) the appraisal of emotions in oneself (SEA); ii) the appraisal of emotions in others (OEA); iii) use of one's own emotions (UOE); and iv) regulation of one's own emotions (ROE). The structure of Wong and Law's (2002) 16-item scale conforms to Salovey and Mayer's (1990) emotional intelligence construct.

Law, Wong and Song (2004) used a two-study/four-sample design to investigate the construct validity of Wong and Law's (2002) measure of emotional intelligence. They reported that the four emotional intelligence sub-scales have acceptable convergent and discriminant validity and that the four sub-scales are distinct from, but correlated to various personality dimensions, such as those in McCrea and Costa's (1985) Big Five Personality Inventory. We used Wong and Law's (2002) 16-item measure because of our concern over the task demand on participants. Ability tests of emotional intelligence place considerable task demands on participants: The MSCEIT consists of 141 items. Additionally, our measure of combinative leadership style places considerable task demands on participants.

\section{Results}

We used AMOS 18.0 to conduct a confirmatory factor analysis on Wong and Law's (2002) four-component emotional intelligence instrument. As shown in Table 1, the four-factor model provides a satisfactory fit for the data. We then compared Wong and Law's (2002) four-factor model to all other possible models, which are as follows: A second-order factor model; six three-factor models in which two of the components were combined; three twofactor models in which each factor comprises two components; four two-factor models in 
which one factor comprises two components; and a single-factor model. As shown in Table 1, all of the Chi-Square differences between the four-factor model and the other models are significant thereby indicating that, of all the models, the four-factor model fits the data best.

(Insert Table 1 about here)

The means, correlations, and internal reliabilities for the four emotional intelligence subscales are in Table 2. All of the scales have satisfactory internal reliability according to Nunnaly's (1976) 0.7 criterion. The results of the factor analyses and the reliability analyses for emotional intelligence are consistent with the results of other studies (e.g., Wong and Law, 2002; Law et al., 2004) that have used the same measure.

Emotional intelligence is not significantly correlated with either age $(r=-.03, \mathrm{p}>0.05)$ or work experience $(r=-.04, \mathrm{p}>0.05)$. There is a non-significant gender difference in emotional intelligence $(\mathrm{t}=0.5, \mathrm{p}>0.05)$. There are non-significant differences between the four educational groups in emotional intelligence $\left(\mathrm{F}=1.5, \mathrm{df}_{1}=3, \mathrm{df}_{2}=200, \mathrm{p}>0.05\right)$.

(Insert Table 2 about here)

Table 3 contains the rankings of the four combinative styles. 'Rank 1' indicates favorite style, 'Rank 2' indicates second favorite style, and so on. Friedman's Rank Test revealed a significant difference in the distribution of ranks $\left(\chi^{2}=179.1\right.$, df $\left.=3, \mathrm{p}<0.000\right)$ : As shown in Table 3, the Before style is ranked first more often than are the three other styles whereas the Delayed style is ranked fourth more often and first less often than are the three other styles.

(Insert Table 3 about here) 
Participants were allocated to four groups based on their preferred combinative style. Leaders who prefer the After style are referred to as the 'After Style group', leaders who prefer the Before style are referred to as the 'Before Style group', and so on.

A one-way between-subjects analysis of variance (ANOVA) was used to examine differences in emotional intelligence between the four groups of leaders. Levene's test indicates that the assumption of homogeneity of variance (i.e., homoscedasticity) is not supported $(\mathrm{F}=4.6, \mathrm{p}<0.01)$. We therefore used Brown-Forsythe's test of equality of means because it does not require homoscedasticity. This test reveals a significant difference in emotional intelligence between the four groups of leaders $\left(\mathrm{F}=27.4, \mathrm{df}_{1}=3, \mathrm{df}_{2}=54.0, \mathrm{p}<\right.$ 0.001, $\eta^{2}=0.357$ ). As shown in Table 4, the Before Style group has the highest level of emotional intelligence whilst the Delayed Style group has the lowest level of emotional intelligence.

\section{(Insert Table 4 about here)}

Tamhane's T2 post hoc test was used to further examine differences in emotional intelligence between the four groups of leaders because it is appropriate when the assumption of homogeneity of variance is violated. This test reveals the following: i) the Before Style group has a significantly higher level of emotional intelligence than do all three of the other groups-Hypothesis 1 is supported; ii) the Delayed Style group has a significantly lower level of emotional intelligence than do all three of the other groups-Hypothesis 2 is supported; and iii) the difference in emotional intelligence between the After Style group and the Either Style group is not significant. 
To examine the differences in emotional intelligence between the groups of leaders who prefer different combinative styles, we conducted a one-way multivariate analysis of variance (MANOVA) on the four components of emotional intelligence. Box's M test supports the assumption of homogeneity of variance-covariance $(F=1.7, p>0.001)$. The MANOVA reveals a significant multivariate effect: Pillai's Trace $\left(0.4, p<0.001\right.$, partial $\left.\eta^{2}=0.137\right)$, Wilk's Lambda $\left(0.6, \mathrm{p}<0.001\right.$, partial $\left.\eta^{2}=0.157\right)$, Hotelling's Trace $(0.7, \mathrm{p}<0.001$, partial $\left.\eta^{2}=0.179\right)$, and Roy's Largest Root $\left(0.6, p<0.001\right.$, partial $\left.\eta^{2}=0.387\right)$.

The four univariate effects were examined using one-way between-subjects ANOVAs. According to Levene's test, the homogeneity of variance assumption is not violated for ROE $(\mathrm{F}=1.2, \mathrm{p}>0.05$,$) but is violated for SEA (\mathrm{F}=5.0, \mathrm{p}<0.05)$, OEA $(\mathrm{F}=2.7, \mathrm{p}<0.05)$ and UOE $(\mathrm{F}=4.7, \mathrm{p}<0.05)$. We therefore used the Brown-Forsythe test of equality of means for SEA, OEA, and UOE because this test does not require homoscedasticity.

As shown in Table 4, there are significant differences between the four groups for all four components of emotional intelligence. The findings from the univariate analyses are as follows: i) SEA $\left(F=17.0, p<0.001, \eta^{2}=0.256\right)$; ii) OEA $\left(F=8.70, p<0.001, \eta^{2}=0.140\right)$; iii) $\operatorname{UOE}\left(\mathrm{F}=14.5, \mathrm{p}<0.001, \eta^{2}=0.234\right)$; and iv) $\operatorname{ROE}\left(\mathrm{F}=18.0, \mathrm{p}<0.001, \eta^{2}=0.213\right)$.

We used post-hoc procedures to examine more closely the four univariate effects. We used Bonferroni's test for ROE because it is appropriate when the homogeneity of variance assumption is upheld whereas we used Tamhane $\mathrm{T}^{2}$ test for SEA, OEA, and UOE because it is appropriate when the homogeneity of variance assumption is violated. The findings of the post-hoc tests are presented in Table 5, but only in terms of whether or not the differences are significant in order to simplify the presentation of these findings. 


\section{(Insert Table 5 about here)}

As shown in Table 5, the post-hoc comparisons reveal that leaders who favor the Before style (i.e., the Before Style group) have significantly higher scores on all four components of emotional intelligence than do the three other groups, with two exceptions. One, although the Before Style group has higher UOE than does the Either Style group, the difference is not significant. Two, although the Before Style group has higher ROE than does the After Style group, the difference is not significant.

The post-hoc comparisons also reveal that leaders who favor the Delayed style (i.e., the Delayed Style group) have significantly lower scores on SEA, ROE, and UOE than do the three other groups of leaders. Furthermore, the Delayed style group has significantly lower OEA than does the Before Style group. Finally, there are non-significant differences between the After Style group and the Either Style group on all four aspects of emotional intelligence.

\section{Discussion}

Despite the debate in the literature regarding the relevance of emotional intelligence to leadership, our study provides evidence that the emotional intelligence of leaders may influence micro aspects of leadership style. The main finding of this study is that the emotional intelligence of leaders is related to their favored combinative leadership style. Specifically, leaders who favor the Before style have the highest levels of emotional intelligence and leaders who favor the Delayed style have the lowest levels.

Emotional intelligence can be linked to favored combinative style by considering the psychological cushioning effect of Support. Specifically, Support that is provided 
immediately before Pressure psychologically cushions followers from the negative emotions that Pressure tends to evoke. In contrast, providing Support immediately after Pressure or delaying the provision of Support reduces or possibly eliminates the capacity of Support to mitigate the negative emotions that Pressure can evoke in followers.

We found the Before Style to be the most popular amongst leaders. One explanation for the popularity of the Before Style is that Pressure renders formal authority salient and thus would arguably be likely to induce negative emotions in followers. As a result, leaders with higher levels of emotional intelligence would be more likely than leaders with lower levels of emotional intelligence to prefer the Before style because as emotional intelligence increases, so too does the likelihood of the leader being aware of and sensitive to the negative emotional effects of Pressure on followers.

The findings from this study have theoretical implications with respect to the effects of micro aspects of leadership. Various leadership styles have been proposed over the last few decades and these styles share a commonality: They are all conceptualized in terms of specific leadership behaviors and/or attitudes, and measured by and large via self-reports or reports from followers of the frequency or intensity of these behaviors and/or attitudes. Although this approach to understanding the effects of leadership has a long history and has yielded many insights into leadership phenomena, this approach assumes the effects of specific leadership behaviors are additive because how they are combined is not considered.

A theoretical implication of the finding that leaders differentiated between different configurations of the Pressure and Support statements is that the effects of these behaviors are interactive and not additive. Leadership scholars usually assume that leadership behaviors 
have additive effects: For example, the Consideration-Initiating Structure paradigm and the Transactional-Transformational paradigm.

Although interactions are usually conceptualized and examined using the product-term approach proposed by Saunders (1956), the findings of this study have methodological implications as they show that the interactive effects of leadership behaviors can be demonstrated without resorting to the product-term approach. Further insights into the determinants and effects of leadership style may be possible by adopting the methodology used in this study.

The findings have implications for organizations especially in light of the evidence that demonstrates the importance of emotions in organizational leadership: i) supportive behaviors induce positive emotions in followers (McColl-Kennedy and Anderson, 2002); ii) inducing positive emotions in followers improves their performance (Grossman, 2000); and iii) the negative impact of frustration on follower performance is greater than the positive impact of optimism (McColl-Kennedy and Anderson, 2002). Providing leadership behaviors that are regarded as effective is necessary but not enough because the emotional impact of leadership behaviors appears to depend on how the behaviors are configured.

\section{Key assumptions and limitations}

A key implicit assumption in our work is that leaders do not want to evoke negative emotions in followers. This assumption is limited because some leaders might believe that negative emotions (e.g., fear) are a useful motivator so even if such leaders have high levels of emotional intelligence they would choose a style that evokes negative emotions in followers. 
The responses of the participants may have been influenced by their actual workplace experiences. We did not take into account factors that influence leadership style which participating managers would be likely to encounter on a daily basis such as the relationship with the follower, the follower's level of performance and work experience, the gender of the leader and the gender of the follower, the hierarchical levels of the leader and follower, and the followers' preferred combinative style. These factors provide a possible explanation for the variance in emotional intelligence among leaders who prefer different combinative styles besides issues such as measurement error and response biases.

The selection of participants from a single region is a limitation, as it brings into question the generalizability of the findings. Future studies might find that in different cultural settings, the Delayed style, for example, is the favored combinative style because of different attitudes to authority. Nevertheless, we think that emotional intelligence will be related to preferred combinative style in different samples although the specifics of the relationship may vary in that in some samples emotionally intelligent leaders might favor the After style or the Delayed style due to factors such as normative power distance. We therefore think that the relationship between emotional intelligence and preferred combinative style will hold but differ across cultures: In other words, we think that this relationship is a variform universal.

The methodology employed in this study is a hybrid design that comprised a vignette, rank data, and a Likert-scale questionnaire. The benefit of using a vignette is that it allows the specification of variables (e.g., some aspects of the workplace situation such as stress level) that might influence leadership style. Another advantage of this type of design is that it addresses mono-method issues because we used Likert-scale data for our independent 
variable and ordinal data for our dependent variable.

The validity of using vignettes of hypothetical or artificial situations has long been criticized (e.g., Campbell, 1977) because the findings from such studies are limited to "paper people" and lack the credibility of field-based research. Furthermore, what people say they will do in a particular situation may not necessarily be the same as how they would actually behave in the same situation (Barter \& Renold, 2000). However, this discrepancy is not necessarily problematic if the aim of the research is to examine attitudes, perceptions or values as people may subscribe to a particular norm but behave differently to the norm due to particular reasons such as personal (e.g., ill health) or interpersonal factors (Finch, 1987).

Scenarios have a place in the progression of research on a particular question (Campbell, 1977). In the case of combinative aspects of leadership style and emotional intelligence, scenarios are a useful starting point. The next step is to examine the relationship between combinative styles of leaders and emotional intelligence in actual workplace settings through an observational study and/or a quantitative study in which, for example, followers and leaders are asked for their combinative style preferences and the emotional intelligence of the leaders is measured.

All of the leadership styles were equivalent in that they all provide both Pressure and Support. It might be the case that leaders with lower levels of emotional intelligence may not recognize that Pressure evokes negative emotions in followers and thus may not provide followers with Support regularly, and in the extreme, simply may not provide any Support to followers. Future studies should examine leadership styles that do not provide Support.

We examined only dyadic leadership. It might be the case that a leader's preferred 
combinative style might vary depending on the unit of analysis. For example, a leader might use different combinative styles when addressing a team or the wider organization to that used in a one-on-one situation with a specific follower.

We did not measure other variables that would arguably influence the leader's preferred combinative leadership style. Personality factors such as need for achievement and pro-self orientation might influence one's preferred combinative style.

We used self-reported emotional intelligence and thus the findings could be biased by social desirability (see Rubin and Babbie, 1989) in that participants might have responded in ways that improve their image. Being emotionally intelligent is arguably socially desirable and social desirability may therefore have distorted the measurement of the relationship between emotional intelligence and combinative aspects of leadership style.

\section{Recommendations for further research}

A number of possibilities for future research arise from our study. As mentioned earlier, a qualitative study may be undertaken to enhance our understanding of the link between emotional intelligence and combinative aspects of leadership styles by examining why leaders prefer the different combinative styles. A causality study is also desirable to examine the possible causal relationship between emotional intelligence and combinative aspects of leadership styles by investigating whether training in emotional intelligence influences a leader's preferred combinative style. The results of a causality study would be useful for developing practical tools for the selection, training and development of leaders. Third, the boundaries of our hypothesis could be widened to include situations involving teams or the 
1

2

3

4

5

wider organization, different types of workplaces and situational factors such as the importance of the follower's task, different types of followers, and different cultures. Finally, as mentioned by a reviewer, the "delay threshold" between Support and Pressure could be examined.

The importance of emotional intelligence with regard to the preferred combinative style of leaders may be overridden by cultural factors. For instance, in cultures with high power distance compared to cultures with low power distance it may be inappropriate to always provide followers with both Pressure and Support contiguously because of followers' acceptance of the leader's formal authority. Future studies can be conducted to examine if emotional intelligence is related to the leader's preferred combinative style after controlling for power distance. Finally, future studies could also examine the relationship between a leader's preferred combinative style and traditional outcome variables such as follower commitment, satisfaction and performance. 


\section{References}

Adolphs, R. and Damasio, A. (2001), 'The interaction of affect and cognition: A neurobiological perspective', In Forgas, J.P. and Mahwah, N.J. (eds), The Handbook of Affect and Social Cognition, pp. 27-49, New Jersey, Erlbaum.

Asch, S.E. (1946), 'Forming impressions of personality', Journal of Abnormal and Social Psychology, 41 (3), 258-290.

Asllani, A. and Luthans, F. (2003), 'What knowledge managers really do: An empirical and comparative analysis', Journal of Knowledge Management, 7 (3), 53-66.

Barsade, S. and Gibson, D. (2007), 'Why does affect matter in organizations?', Academy of Management Perspectives, 21 (1), 36-59.

Barter, C. and Renold, E. (2000), 'I wanna tell you a story': Exploring the application of vignettes in qualitative research with children and young people', International Journal of Social Research Methodology, 3 (4), 307-323.

Bass, B.M. (1997), 'Does the transactional-transformational leadership paradigm transcend organizational and national boundaries?', American Psychologist, 52 (2), 130-39.

Bass, B.M. and Stogdill, R.M. (1990), Bass and Stogdill's Handbook of Leadership: Theory, Research, and Managerial Applications, New York: Free Press.

Bono, J., Folds, H.J., Vincent, G. and Muros, J.P. (2007), 'Workplace emotions', Journal of Applied Psychology, 92 (5), 1357-1367.

Bower, G.H. (1991), 'Mood congruity of social judgments', In Forgas, J.P. (ed), Emotion and Social Judgments, pp. 31-53, New York: Pergamon Press. 
Bower, G.H. and Forgas, J.P. (2001), 'Mood and social memory', In Forgas J.P. and Mahwah

N.J. (eds), The Handbook of Affect and Social Cognition, pp. 95-120, New Jersey: Erlbaum.

Braun, V. and Clarke, V. (2013), Successful Qualitative Research: A Practical Guide for

Beginners, London: Sage.

Bruno, L. and Lay, E. (2008), 'Personal values and leadership effectiveness', Journal of

Business Research, 61 (6), 678-683.

Campbell, J.P. (1977), 'The cutting edge of leadership: An overview', In Hunt, J.G. and Larson, L.L. (eds) Leadership: The Cutting Edge, pp. 221-234, Carbondale: Southern Illinois University Press.

Cartwright, S. and Cooper, C.L. (2009), (eds.) The Oxford Handbook of Organizational WellBeing, Oxford, U.K.: Oxford University Press.

Caruso, D.R., Mayer, J.D. and Salovey, P. (2002), 'Emotional intelligence and leadership', In Riggio R.E., Murphy S.E. and Pirozzolo F.J. (eds), Multiple Intelligences and Leadership. pp. 55-75, London: Erlbaum.

Casimir, G. (2001), 'Combinative aspects of leadership style: The ordering and temporal spacing of leadership behaviors', The Leadership Quarterly, 12 (3), 245-278.

Church, A. (1997), 'Managerial self-awareness in high-performing individuals in organizations', Journal of Applied Psychology, 82 (2), 281-292.

Côté, S., Lopes, P., Salovey, P., and Miners, C. (2010), 'Emotional intelligence and leadership emergence in small groups', The Leadership Quarterly, 21 (3), 496-508.

Corkery, J. (1992), 'The use of vignettes in sentencing studies of English magistrates', International Journal of the Sociology of Law, 20 (3), 253-270. 
Deci, M.R. and Ryan, L.D. (2000), 'Intrinsic and extrinsic motivations: Classic definitions and new directions', Contemporary Educational Psychology, 25 (1), 54-67.

Doty, D.H. and Glick, W. (1994), 'Typologies as a unique form of theory building: Toward improved understanding and modelling', Academy of Management Review, 19 (2), 230251.

Fleishman, E.A. (1973), 'Twenty years of consideration and initiating structure', In Fleishman, E.A. and Hunt, J.G. (eds), pp. 1-37, Current Developments in the Study of Leadership. Carbondale: Southern Illinois University Press.

Fox, S. and Stalworth, L. (2010), 'The battered apple: An application of stressor-emotioncontrol/support theory to teachers' experience of violence and bullying', Human Relations, $63(7), 927-954$.

Fredrickson, B.L. (2001), 'The role of positive emotions in positive psychology: The broaden and build theory of positive emotions', American Psychologist, 56 (3), 218-226.

Finch, J. (1987), 'The vignette technique in survey research', Sociology, 21 (1), 105-114 Frijda, N. (1992), 'The empirical status of the laws of emotion', Cognition and Emotion 6 (6), 467-477.

Frijda, N. (1993), 'Moods, emotion episodes and emotions', In Lewis, M. and Haviland, J. (eds), Handbook of Emotions, pp. 381-403, New York: Guildford Press.

Fulk, J. and Wendler, E. (1982), 'Dimensionality of leader-subordinate interactions: A pathgoal investigation', Organizational Behavior and Human Performance, 30 (2), 241-264.

George, J.M. (2000), 'Emotions and leadership: The role of emotional intelligence', Human Relations, 53 (8), 1027-1055. 
Gioia, D.A. and Poole, P.P. (1984), 'Scripts in organizational behavior', Academy of Management Review, 9 (3), 449-459.

Goleman, D. (1995), Emotional Intelligence. New York: Bantam Books.

Goleman, D., Boyatzis, R. and McKee, A. (2004), Primal Leadership: Learning to Lead with Emotional Intelligence, Boston: Harvard Business School Press.

Grossman, R.J. (2000), 'Emotions at Work', Health Forum Journal 43 (5), 18-22.

Hafsi, M. (1988), 'A psychoanalytic approach to performance-maintenance (PM) leadership theory', Psychologia, 31 (1), 72-83.

Halpin, A.W. (1955), 'The leadership ideology of aircraft commanders', Journal of Applied Psychology, 39 (2), 82-84.

House, R.J. (1971), 'A path-goal theory of leader effectiveness', Administrative Science Quarterly, $16(3), 321-338$.

House, R.J. (1977), A 1976 theory of charismatic leadership. In: Hunt, J.G. and Larson, L.L. (eds) pp. 189-207, Leadership: The Cutting Edge, Carbondale: South Illinois University Press.

House, R.J. (1987), 'The “all things in moderation” leader', Academy of Management Review, $12(1), 164-169$.

Hull, C.L. (1945), 'The discrimination of stimulus configurations and the hypothesis of afferent neural interaction', Psychological Review, 52 (3), 133-142.

James, K., Mann, J. and Creasy, J. (2007), 'Leaders as lead learners: A case example of facilitating collaborative leadership learning for school leaders', Management Learning, 38 (1), 79-94. 
Judge, T., Piccollo, R. and Ilies, R. (2004), 'The forgotten ones? The validity of consideration and initiating structure in leadership research', Journal of Applied Psychology, 89 (1), 3651.

Kerr, R., Garvin, J., Heaton, N. and Boyle, E. (2006), 'Emotional intelligence and leadership effectiveness', Leadership and Organization Development Journal, 27 (4), 265-279.

Komaki, J.L., Zlotnick, S. and Jensen, M. (1986), 'Development of an operant-based taxonomy and observational index of supervisory behavior', Journal of Applied Psychology, 71 (2), 260-269.

Law, K.S., Wong, C.S. and Song, L.J. (2004), 'The construct and criterion validity of emotional intelligence and its potential utility for management studies', Journal of Applied Psychology, 89 (3), 483-496.

Lee, P., Gillespie, N., Mann, L. and Wearing, A. (2010), 'Leadership and trust: Their effect on knowledge sharing and team performance', Management Learning, 41 (4), 473-491.

Lopes, P., Salovey, P., Côté, S. and Beers, M. (2005), 'Emotion regulation abilities and the quality of social interaction', Emotion 5 (1), 113-118.

Markus, H. and Zajonc, R. (1985), 'The cognitive perspective in social psychology’, In Lindzey G. and Aronson E. (eds) pp. 137-231, Handbook of Social Psychology, New York: Random House.

Mayer, J.D., Caruso, D.R. and Salovey, P. (2000), 'Selecting a measure of emotional intelligence: The case for ability scales', In Baron, R. and Parker, J.D. (eds) The Handbook of Emotional Intelligence: Theory, Development, Assessment at Home, School, and in the Workplace, pp. 320-342, San Francisco: Jossey-Bass. 
Mayer, J.D. and Salovey, P. (1993), 'The intelligence of emotional intelligence', Intelligence, $17(4), 433-442$.

Mayer, J.D. and Salovey, P. (1997), 'What is emotional intelligence?', In Salovey P. and Sluyter D. (eds), pp. 3-31, Emotional Development and Emotional Intelligence: Educational Implications, New York: Basic Books.

Mayer, J., Salovey, P. and Caruso, D. (2002), Manual for the MSCEIT (Mayer-SaloveyCaruso Emotional Intelligence Test), Toronto: Multi-Health Systems.

McColl-Kennedy, J.R. and Anderson, R.D. (2002), 'Impact of leadership style and emotions on subordinate performance', The Leadership Quarterly, 13 (5), 545-559.

McCrae, R.R. and Costa, Jr P.T. (1987), 'Validation of the five-factor model of personality across instruments and observers', Journal of Personality and Social Psychology, 52 (1), 81-90.

Mignonac, K. and Herrbach, O. (2004), Linking work events, affective states and attitudes: an empirical study of managers' emotions. Journal of Business and Psychology, 19 (2), $21-40$.

Misumi, J. (1985), The Behavioral Science of Leadership: An Interdisciplinary Japanese Research Program, Ann Arbor: University of Michigan Press.

Misumi, J. and Peterson, M. (1985), 'The performance-maintenance (PM) theory of leadership: Review of a Japanese research program', Administrative Science Quarterly, 30 (2), 198-223.

Nottenberg, G. and Shoben, E.J. (1980), 'Scripts as linear orders', Journal of Experimental Social Psychology, 16 (4), 329-347. 
Nunnaly, J.C. (1978), Psychometric Theory, New York: McGraw Hill.

Ouweneel, E., Le Blanc, P., Schaufeli, W. and van Wijhe, C. (2012), 'Good morning, good day: A diary study on positive emotions, hope, and work engagement', Human Relations, $65(9), 1129-1154$.

Pavlova M., Sokolov, A.A. and Sokolov, A. (2005), 'Perceived dynamics of static images enables emotional attribution', Perception, 34 (9), 1107-1116.

Peterson, M.F., Smith, P.B. and Tayeb, M.H. (1993), 'Development and use of English versions of Japanese PM leadership measures in electronic plants', Journal of Organizational Behavior, 14 (3), 251-267.

Peterson, S. and Luthans, F. (2003), 'The positive impact and development of hopeful leaders', Leadership and Organization Development Journal, 24 (1), 26-31.

Rubin, A. and Babbie, E. (1989), Research Methods for Social Work, Belmont: Wadsworth. Saunders, D. (1956), 'Moderator variables in prediction', Educational and Psychological Measurement, 16 (2), 209-222.

Salovey, P. and Mayer, J.D. (1990), 'Emotional intelligence', Imagination, Cognition and Personality, 9 (3), 185-211.

Weisinger, H. (1998), Emotional Intelligence at Work: The Untapped Edge for Success, San Francisco: Jossey-Bass.

Weiss, H. and Cropanzano, R. (1996), 'Affective events theory: A theoretical discussion of the structure and consequences of affective experiences at work', In Staw, B and Cummings, L (eds) Research in Organizational Behavior, pp. 1-74, Greenwich, CT: JAI Press. 
Wolff, S., Pescosolido, A. and Druskat, V. (2002), 'Emotional intelligence as the basis of leadership emergence in self-managing teams', The Leadership Quarterly, 13 (5), 505-522.

Wong, C. and Law, K. (2002), 'The effects of leader and follower emotional intelligence on performance and attitude: An exploratory study', The Leadership Quarterly, 13 (3), $243-$ 274.

Yukl, G. (2002), Leadership in Organizations (5th ed.), Upper Saddle River: Prentice Hall.

Zineldin, M. and Hytter, A. (2012), 'Leaders' negative emotions and leadership styles influencing subordinates' well-being', The International Journal of Human Resource Management, 23 (3), 748-758. 
Table 1

Findings from the Confirmatory Factor Analyses

\begin{tabular}{|c|c|c|c|c|c|c|}
\hline & $\chi^{2}(\mathrm{df})$ & $\Delta \chi^{2}(\Delta \mathrm{df})^{\mathrm{a}}$ & RMSEA & RMR & CFI & NNFI \\
\hline Four-factor & $175.5(98)$ & -------- & .062 & .034 & .95 & .93 \\
\hline Second-Order Factor & $182.3(100)$ & $6.8(2)^{*}$ & .064 & .038 & .94 & .93 \\
\hline Three-factor (ROE+SEA) & $317.2(101)$ & $141.7(3)^{* * *}$ & .103 & .055 & .85 & .82 \\
\hline Three-factor (ROE+OEA) & $294.1(101)$ & $118.6(3) * * *$ & .097 & .051 & .86 & .84 \\
\hline Three-factor (ROE+UOE) & $319.0(101)$ & $143.5(3) * * *$ & .103 & .059 & .85 & .82 \\
\hline Three-factor (SEA+OEA) & $366.7(101)$ & $191.2(3) * * *$ & .114 & .064 & .81 & .78 \\
\hline Three-factor (SEA+UOE) & $265.9(101)$ & $90.4(3) * * *$ & .090 & .053 & .88 & .86 \\
\hline Three-factor (OEA+UOE) & $337.9(101)$ & $162.4(3)^{* * *}$ & .108 & .081 & .83 & .80 \\
\hline Two-factor (ROE+OEA) & $384.5(103)$ & $209.0(5)^{* * *}$ & .116 & .065 & .80 & .77 \\
\hline Two-factor (ROE+SEA) & $478.3(103)$ & $302.8(5) * * *$ & .134 & .091 & .74 & .69 \\
\hline Two-factor (ROE+UOE) & $505.4(103)$ & $329.9(5) * * *$ & .139 & .079 & .72 & .67 \\
\hline Two-factor $(\mathrm{SEA}+\mathrm{OEA}+\mathrm{UOE})$ & $480.1(103)$ & $304.6(5) * * *$ & .134 & .075 & .73 & .69 \\
\hline Two-factor (OEA+ UOE+ROE) & $449.3(103)$ & $273.8(5)^{* * *}$ & .129 & .085 & .76 & .72 \\
\hline Two-factor (SEA+ UOE+ROE) & $402.3(103)$ & $226.8(5)^{* * *}$ & .120 & .068 & .79 & .75 \\
\hline Two-factor $(\mathrm{SEA}+\mathrm{OEA}+\mathrm{ROE})$ & $474.5(103)$ & $299.0(5) * * *$ & .133 & .071 & .74 & .70 \\
\hline One-factor & $586.2(104)$ & $410.7(6) * * *$ & .151 & .083 & .66 & .61 \\
\hline
\end{tabular}

${ }^{a}$ All of the alternative models are compared to the hypothesized four-factor model.

$* \mathrm{p}<.05, * * * \mathrm{p}<.001$

$\mathrm{SEA}=$ self-emotional appraisal, OEA $=$ others' emotional appraisal, $\mathrm{UOE}=$ use of emotion, $\mathrm{ROE}=$ regulation of emotion. 
Table 2

Means, Standard Deviations, Correlations ${ }^{a}$, and Internal Reliabilities ${ }^{b}$ for the Four Subscales of Wong and Law's 16-item Emotional Intelligence Questionnaire

\begin{tabular}{lccccc}
\hline & Mean (SD) & 1 & 2 & 3 & 4 \\
\hline 1. SEA & $3.80(.73)$ & .83 & & & \\
2. OEA & $3.56(.67)$ & .53 & .89 & .41 & .78 \\
3. ROE & $3.91(.60)$ & .51 & .46 & .32 & .76 \\
4. UOE & $3.97(.76)$ & .37 & .46 & \\
\hline
\end{tabular}

${ }^{\mathrm{a}}$ All correlations are significant at $\mathrm{p}<.001$.

${ }^{\mathrm{b}}$ Cronbach Alphas are in bold on the diagonal.

SEA = self-emotional appraisal, OEA = others' emotional appraisal, UOE = use of emotion, $\mathrm{ROE}=$ regulation of emotion . 
Table 3

Frequencies, in Percentages, of the Rankings of the Four Combinative Styles

\begin{tabular}{lcccc}
\hline & Before & After & Either & Delayed \\
\hline Rank 1 & 50 & 22 & 21 & 8 \\
Rank 2 & 28 & 24 & 41 & 7 \\
Rank 3 & 14 & 46 & 25 & 15 \\
Rank 4 & 8 & 9 & 12 & 70 \\
\hline
\end{tabular}


Table 4

Mean (SD) and One-way ANOVA results for Overall Emotional Intelligence and its components for the four groups of leaders

\begin{tabular}{llllll}
\hline Favored style & EI & SEA & OEA & UOE & ROE \\
\hline Before $(\mathrm{n}=101)$ & $4.0(.4)$ & $4.1(.5)$ & $3.8(.6)$ & $4.2(.6)$ & $4.1(.6)$ \\
After $(\mathrm{n}=44)$ & $3.7(.4)$ & $3.7(.7)$ & $3.5(.6)$ & $3.8(.6)$ & $3.9(.5)$ \\
Either $(\mathrm{n}=43)$ & $3.7(.5)$ & $3.6(.7)$ & $3.4(.6)$ & $3.9(.8)$ & $3.8(.6)$ \\
Delayed $(\mathrm{n}=16)$ & $2.9(.6)$ & $2.7(.9)$ & $2.9(.9)$ & $2.9(1.0)$ & $3.0(.3)$ \\
F-value & $27.4 * * *$ & $18.0 * * *$ & $8.7 * * *$ & $14.5 * * *$ & $18.0 * * *$ \\
Eta Square $\left(\eta^{2}\right)$ & 0.357 & 0.256 & 0.140 & 0.234 & 0.213 \\
\hline$* * * \mathrm{p}<.001$ & & & \\
$\begin{array}{l}\text { EI }=\text { overall emotional intelligence (sum of four sub-scales), SEA = self-emotional appraisal, } \\
\text { OEA = others' emotional appraisal, UOE = use of emotion, ROE = regulation of emotion. }\end{array}$
\end{tabular}


Table 5

Post-hoc Findings for Differences in the Four Components of Emotional Intelligence

between the Four Favored-Style Groups

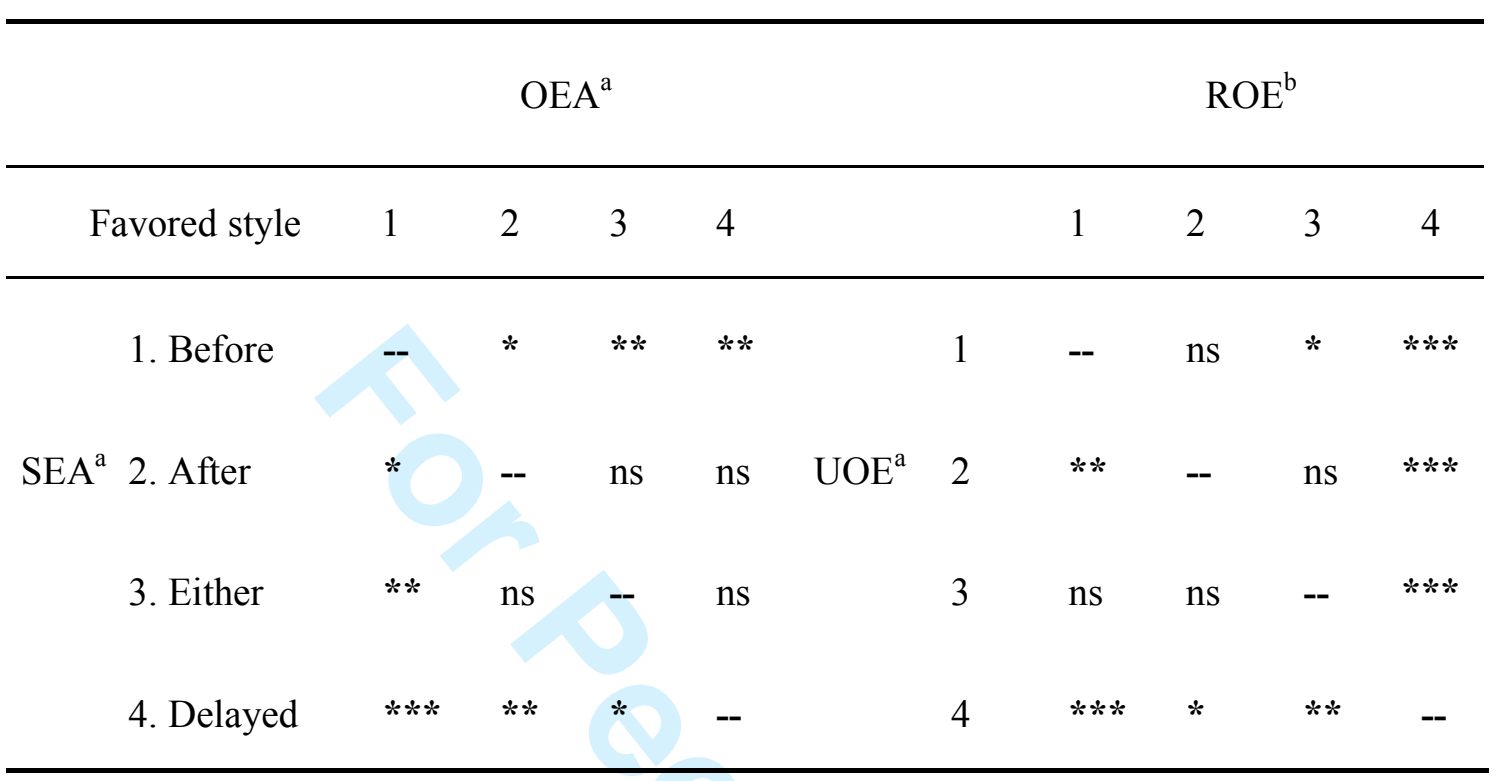

${ }^{a}$ Tamhane post-hoc test significance level is reported.

${ }^{\mathrm{b}}$ Bonferroni post-hoc test significance level is reported

$* \mathrm{p}<.05, * * \mathrm{p}<.01, * * * \mathrm{p}<.001, \mathrm{~ns}=$ not significant.

SEA $=$ self-emotional appraisal OEA $=$ others' emotional appraisal, $\mathrm{UOE}=$ use of emotion, $\mathrm{ROE}=$ regulation of emotion. 